\title{
Life-threatening acute water intoxication in a woman undergoing hysteroscopic myomectomy: a case report and review of the literature
}

Chen-Yi Liao ${ }^{1 \dagger}$, Chang-Han Lo ${ }^{2 \dagger}$, Mu-Xian Yư ${ }^{3}$, Wei-Hung Chan ${ }^{4}$, Kuang-yu Wei ${ }^{2}$, Min-Feng Tseng ${ }^{2}$ and Chia-Chao $\mathrm{Wu}^{2^{*}}$

\begin{abstract}
Background: Acute water intoxication after hysteroscopy is a rare, life-threatening condition, often accompanied with delayed diagnosis owing to masked symptoms because of general anesthesia.

Case presentation: Herein we presented a 39-year-old female who presented with cardiac arrest after hysteroscopic myomectomy because of acute water intoxication and survived after extracorporeal membrane oxygenation, continuous venous-venous hemofiltration, and aggressive high sodium fluid resuscitation.
\end{abstract}

Conclusion: Failure to recognize and treat this condition appropriately may lead to potentially lethal cardiopulmonary complications.

Keywords: Acute water intoxication, Cardiopulmonary failure, Hysteroscopic myomectomy, Extracorporeal membrane oxygenation

\section{Background}

Acute water intoxication (AWI, acute hyponatremia) typically occurs when a large quantity of electrolyte-free water is administered to a person with impaired water excretion ability. AWI develops within $48 \mathrm{~h}$ and usually manifests as headache, nausea, vomiting, visual disturbances, seizure, coma, and irreversible brain damage. Lifethreatening events such as neurogenic stunned myocardium, noncardiogenic pulmonary edema, brain edema, and respiratory arrest can occur [1]. Postoperative AWI is a commonly encountered scenario occurring in $1 \%$ of patients because of a combination of hypotonic fluid administration and non-osmotic stimuli. Operations like transurethral resection of the prostate, transcervical resection of the endometrium, transcervical resection of fibroids, and hysteroscopic myomectomy are occasionally

\footnotetext{
* Correspondence: wucc@mail.ndmctsgh.edu.tw

${ }^{\dagger}$ Chen-Yi Liao and Chang-Han Lo contributed equally to this work and shared first authorship.

${ }^{2}$ Division of Nephrology, Department of Medicine, Tri Service General Hospital, Pen-Hu Branch, Peng-Hu, Taiwan

Full list of author information is available at the end of the article
}

associated with postoperative AWI owing to the administration of hypotonic irrigation media. Herein we presented the case of a young woman who suffered a cardiac arrest resulting from AWI during hysteroscopic myomectomy and was successfully treated with extracorporeal membrane oxygenation (ECMO), continuous venous-venous hemofiltration $(\mathrm{CVVH})$, and prompt correction of plasma sodium.

\section{Case presentation}

A 39-year-old healthy woman with normal menstrual periods presented to the emergency department because of postoperative cardiac arrest after a hysteroscopic myomectomy with general anesthesia. Preoperative blood tests revealed no anomalies. According to the local health facility, she had been irrigated with $8000 \mathrm{~mL}$ of $5 \%$ dextrose water with monopolar electrosurgery and subsequently underwent 35 min of cardiopulmonary resuscitation with medication including sodium bicarbonate $266 \mathrm{mmol}$ (16 ampules) and other inotropic agents. On admission, her 
body weight was $74 \mathrm{~kg}$ (compared to presurgery body weight $62 \mathrm{~kg}$ ); body mass index of 26.2; equal and dilated pupils; Glasgow coma scale of E1VTM1; low body temperature $\left(32.9^{\circ} \mathrm{C}\right)$, rapid heart rate $(117 \mathrm{bpm})$, hypotension $(74 / 47 \mathrm{mmHg})$, desaturation with $\mathrm{SpO}_{2}$ of $86 \%$ and less than $100 \% \mathrm{FiO}_{2}$ support after intubation, and she was placed on ventilator support with a lungprotective strategy. Her laboratory tests revealed isoosmotic hyponatremia, severe metabolic acidosis with hypercapnia and hypoxemia, hypoalbuminemia, and hemolysis with disseminated intravascular coagulopathy. The patient received a significant amount of sodium bicarbonate, so the acidosis was most likely much more severe at presentation and the acidosis may have been due to lactic acidosis. (Table 1).

The patient was immediately resuscitated with $300 \mathrm{~mL}$ of intravenous $3 \%$ sodium chloride within $4 \mathrm{~h}$ for acute

Table 1 Biochemical studies on admission

\begin{tabular}{|c|c|c|}
\hline Study & Values & Reference range \\
\hline \multicolumn{3}{|l|}{ Plasma } \\
\hline $\mathrm{PH}$ & $7.155^{\mathrm{a}}$ & $7.35-7.45$ \\
\hline $\mathrm{PCO} 2, \mathrm{mmHg}$ & $50^{a}$ & $35.0-45.0$ \\
\hline $\mathrm{PO} 2, \mathrm{mmHg}$ & 60.1 & $75-100$ \\
\hline $\mathrm{HCO}^{-}, \mathrm{mmol} / \mathrm{L}$ & $17.2^{a}$ & $22.0-27.0$ \\
\hline $\mathrm{Na}^{+}, \mathrm{mmol} / \mathrm{L}$ & $125^{a}$ & $136-145$ \\
\hline Osmolarity, mOsm/kgH2O & 277 & $275-295$ \\
\hline $\mathrm{K}^{+}, \mathrm{mmol} / \mathrm{L}$ & 3.8 & $3.5-5.1$ \\
\hline $\mathrm{Cl}^{-}, \mathrm{mmol} / \mathrm{L}$ & 98 & $98-107$ \\
\hline Glucose, mg/dL & 334 & $74-100$ \\
\hline BUN, mmol/L & 13 & $7-25$ \\
\hline Creatinine, mg/d & $1.3^{\mathrm{a}}$ & $0.7-1.2$ \\
\hline Albumin, g/dL & $<1.5^{\mathrm{a}}$ & $3.5-5.7$ \\
\hline Hemoglobin, mg/dL & 11.0 & $12.0-16.0$ \\
\hline Haptoglobin, mg/d & 7.3 & $36.0-195.0$ \\
\hline $\mathrm{LDH}, \mathrm{U} / \mathrm{L}$ & 1352 & $140-271$ \\
\hline Lactic acid mmol/L & 10.9 & $0.5-2.2$ \\
\hline Total bilirubin, mg/d & 3.5 & 0.3 to 1.0 \\
\hline Direct bilirubin, mg/d & 0.5 & $<0.2$ \\
\hline PT, sec & 28.6 & $8.0-12.0$ \\
\hline aPTT, sec & 65.4 & $23.9-35.5$ \\
\hline D-dimer, FEU & $>35.20$ & $<0.5$ \\
\hline \multicolumn{3}{|c|}{ Endocrine survey (Before discharge) } \\
\hline Cortisol,ug/dL & 15.25 & \\
\hline $\mathrm{ACTH}, \mathrm{pg} / \mathrm{mL}$ & 19.6 & $0.1-46$ \\
\hline $\mathrm{TSH}, \mathrm{ulU} / \mathrm{ml}$ & 5.41 & $0.25-5.00$ \\
\hline Free $T 4, n g / d l$ & 1.29 & $0.89-1.78$ \\
\hline
\end{tabular}

AST aspartate aminotransferase; $A L T$ alanine aminotransferase; $A C T H$ adrenocorticotropic hormone; $T S H$ thyroid-stimulating hormone

${ }^{a}$ indicates abnormal values hyponatremia. Because of altered consciousness, mannitol and furosemide were administered for suspected brain edema. Inotropic agents and vasopressors were administered for profound shock status. Initial chest X-ray and chest $\mathrm{CT}$ were compatible with acute pulmonary edema (Fig. 1a). Echocardiogram revealed severe hypokinesia of the left ventricular apex with ejection fraction of $35 \%$.Although initial troponin level was $1.944 \mathrm{ng} / \mathrm{mL}$, subsequently, the levels increased to 18.46 and $20.73 \mathrm{ng} /$ $\mathrm{mL}$. After resuscitation, serum sodium level increased from $125 \mathrm{mmol} / \mathrm{L}$ to $139 \mathrm{mmol} / \mathrm{L} 3 \mathrm{~h}$ after admission and was $141 \mathrm{mmol} / \mathrm{L} 7 \mathrm{~h}$ after admission; however, the patient remained comatose. Brain CT 1 day after admission revealed no evidence of focal swelling. Subsequently, she was treated with $\mathrm{CVVH}$ to remove accumulated fluid from acute pulmonary edema and anuric acute kidney injury, which occurred despite the use of diuretics. Because of acute respiratory distress syndrome with severe hypercapnia, hypoxemia, and poor motion of the heart wall, the patient received venous-arterial ECMO. Further follow-up laboratory examinations revealed unremarkable thyroid function and adrenal function (Table 1). As follow-up echocardiography revealed improved left ventricular diastolic and systolic function with ejection fraction of $57 \%$, the patient was successfully weaned off ECMO on the day 9; she regained consciousness on day 10 and was successfully extubated on the day 13 of admission (Fig. 1). She was relocated to the ward on postoperative day 25 and was released from the hospital on postoperative day 28 without any detectable sequelae.

\section{Discussion and conclusions}

Hysteroscopic procedures are performed using an endoscope, with intrauterine distention using either gas $\left(\mathrm{CO}_{2}\right)$ or fluid distending media. The procedure can lead to life-threatening events if systemic absorption of distending media such as AWI occurs $(0.06-0.2 \%$ of women) [2].

Excessive absorption of non-electrolyte distending media such as $1.5 \%$ glycine $(200 \mathrm{mOsm} / \mathrm{L}), 3 \%$ sorbitol $(165 \mathrm{mOsm} / \mathrm{L})$, and $5 \%$ dextrose can cause AWI [3]. In patients undergoing hysteroscopic procedures, symptoms develop when serum sodium concentration drops below $125 \mathrm{mmol} / \mathrm{L}$ [3].

Premenopause, hypoxia, and young age are common risk factors associated with worsened prognosis of hyponatremia encephalopathy in postoperative AWI. The relative risk of death or permanent neurological damage from hyponatremic encephalopathy is 30 times higher for women than men and 25 times greater for menstruating compared to postmenopausal females [4]. The proposed mechanism is associated with the inhibitory effects of estrogen on the ATPase pump that regulates 


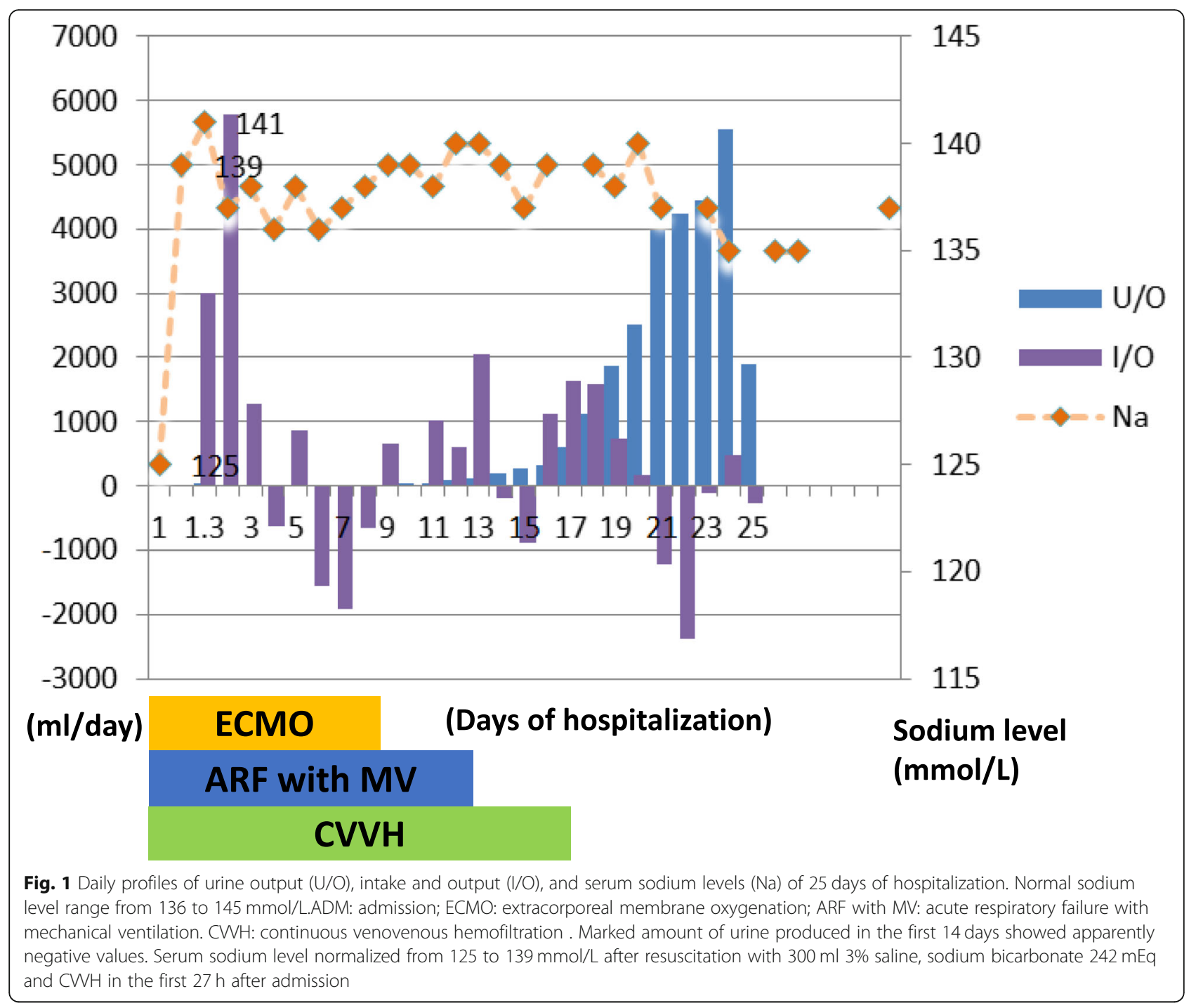

electrolyte flow through the blood-brain barrier [5]. Additionally, the effects of vasopressin on cerebral vasoconstriction and hypoperfusion of brain tissue also precipitate the risk of hyponatremic encephalopathy in premenopausal women [6]. The differential diagnosis of cardiopulmonary failure and acute consciousness disturbance after hysteroscopy in the present case included AWI, acute gas embolism, and thromboembolism. Irrigation media included hypotonic, normal tonic, and gaslike $\mathrm{CO}_{2}$. Gas media contribute to a higher risk of developing acute air embolism during hysteroscopy. Although gas media was not administered in the present case, the incidence of acute air embolism is higher in patients undergoing bipolar electrosurgery, especially when more than $1000 \mathrm{~mL}$ of fluid is absorbed [3, 6]. In the present case, we believed that the patient suffered from postoperative AWI (lower than $125 \mathrm{mmol} / \mathrm{L}$ ) before admission to the emergency department because of the large amount of sodium bicarbonate $(266 \mathrm{mmol})$ resuscitation during CPR.

Common risk factors of AWI in patients undergoing hysteroscopic procedures include prolonged operative time, large irrigation fluid amount, higher pressure created by the intrauterine media with higher systemic absorption, visceral perforation, and general anesthesia $[3,6]$. The actual volume of distension fluid often exceeds the declared volume by $2.8-10 \%$ owing to incomplete collection of spilled fluids or false lower fluid deficit as a result of significant bleeding during hysteroscopic surgery as in the present case [7]. The AAGL Guidelines consensus view is that once a fluid deficit of $1000 \mathrm{ml}$ of hypotonic solution or $2500 \mathrm{ml}$ with an isotonic solution is reached immediate suspension of the procedure is imperative. When highviscosity distending media are used, the maximum infused volume should not exceed $500 \mathrm{~mL}$, and in the elderly and those with cardiopulmonary compromise should not 
exceed $300 \mathrm{~mL}$ [6]. Patients with decreased serum sodium of $10 \mathrm{meq} / \mathrm{L}$, which is representative of $1000 \mathrm{~mL}$ of hypoosmotic irrigation fluid absorption in women undergoing hysteroscopy, are more are likely to develop neurological symptoms $[4,6]$. Thus, we believe that irrigation of 8000 $\mathrm{mL}$ of dextrose water with absorption of more than 1000 $\mathrm{mL}$ occurred in our patient. Sudden-onset neurogenic stunned myocardium has been reported after AWI especially in a younger woman [1]. Neither irrigation fluid absorption related non-cardiogenic pulmonary edema nor postcardiopulmonary resuscitation pulmonary edema can lead to severe hypoxemia, which is a strong predictor of high mortality in AWI [4].The danger of combined hypoxemia and hyponatremia should be stress out because hypoxemia impairs the ability of the.

brain to adapt to hyponatraemia, leading to a vicious cycle of worsening hyponatraemic encephalopathy. Hyponatraemia cause derangement in both cerebral.

blood flow and arterial oxygen content. Symptomatic hyponatremia can lead to hypoxemia through both noncardiogenic pulmonary edema and hypercapnic respiratory failure. Besides, the cerebral edema from hyponatremia also lead to non-cardiogenic pulmonary edema [4]. Thus, early recognition of AWI with the aid of ECMO support in cardiopulmonary decompensation is vital. With the presentation of anuric acute kidney injury with severe metabolic acidosis [8], hemodialysis can rapidly correct hyponatremia, acidosis, osmotic derangements, and volume expansion as well as remove non-electrolyte irrigation fluid. In hemodynamically unstable conditions, CVVH is the better choice [9].

Plasma sodium level slowly and continuously shifts toward normal with CVVH treatment, rendering it a safe and effective option for the treatment of acute hyponatremia. Moreover, the rate of sodium correction may be controlled by changing the dialysate or the delivery and composition of the replacement fluid [8]. In the present case, the sodium correction ratewas rapid $(16 \mathrm{mmol} / \mathrm{L}$ within $7 \mathrm{~h}$ ), relative to acute symptomatic hyponatremia without developing osmotic demyelination. Currently, no data from controlled trials exist to enable the examination of maximal correction rate in AWI after hysteroscopy. A correction rate of $25 \mathrm{mEq} / \mathrm{L}$ is generally recommended within $48 \mathrm{~h}$. The correction rates reported by most publications were higher than that in the present case despite developing osmotic demyelination [10].

The utmost caution is necessary when looking for hidden risk factors prior to hysteroscopic procedures. During surgery, constant vigilance regarding change in vital signs, input, output, irrigation fluid amount, and duration are critical in preventing AWI. Once AWI manifests, rapid elimination of free water deficits and normalization of sodium levels by adopting measures such as hypertonic saline and CRRT in anuric cases, and ECMO therapy in cases of severe cardiopulmonary decompensation is essential.

\section{Abbreviations}

AWI: Acute water intoxication; CPR: Cardiopulmonary resuscitation;

CT: Computed tomography; CWH: Contionus venous-venous hemofiltration; ECMO: Extracorporeal membrane oxygenation

\section{Acknowledgements}

We acknowledge Dr. Yu-Jeui Hsu for providing his personal experience in acute hyponatremia in the hospital setting. We thank to the great case presentation by the resident Cho-Hao Lee and intern Ta-Hsin Tsung.

\section{Authors' contributions}

CYL and CHL participated in writing the manuscript. MXY carried out the study and is the original physician of the patient. CWH participated in providing knowledge of the disease etiology and provide possible differtial diagnosis. KYW, and TMF collected information of patient and wrote the contents of Clinical course of the manuscript. CCW helped draft the manuscript and revised it. All authors read and approved the final manuscript.

\section{Funding}

This study was supported by research grants from Tri-Service General Hospital, Peng-Hu branch (TSGH-PH-107-6).

\section{Availability of data and materials}

Not applicable.

The patient's data is only available from our hospital eletronic database which is not open to the public

\section{Ethics approval and consent to participate}

This study was exempted from institutional review board approval because it was a case review and secondary analysis.

\section{Consent for publication}

Written informed consent was obtained from the patient for publication of this Case report and any accompanying images. A copy of the written consent is available for.

review by the Editor of this journal.

\section{Competing interests}

The authors declare that they have no competing interests.

\section{Author details}

${ }^{1}$ Kaohsiung Armed Forces General Hospital, Kaohsiung, Taiwan. ${ }^{2}$ Division of Nephrology, Department of Medicine, Tri Service General Hospital, Pen-Hu Branch, Peng-Hu, Taiwan. ${ }^{3}$ Division of Nephrology, Department of Internal Medicine, Tri-Service General Hospital, National Defense Medical Center, No. 325, Section 2, Cheng-Kung Road, Neihu, 114 Taipei, Taiwan. ${ }^{4}$ Department of Obstetrics and Gynecology, Tri-Service General Hospital, National Defense Medical Center, Taipei, Taiwan.

Received: 3 September 2018 Accepted: 29 January 2020

References

1. Losonczy LI, Lovallo E, Schnorr CD, Mantuani D. Drinking to near death-acute water intoxication leading to neurogenicstunned myocardium. Am J Emerg Med. 2016;34:119.e3-4.

2. Aydeniz B, Gruber IV, Schauf B, Kurek R, Meyer A, Wallwiener D. A multicenter survey of complications associated with 21,676 operative hysteroscopies. Eur J Obstet Gynecol Reprod Biol. 2002;104:160-4.

3. Umranikar S, Clark TJ, Saridogan E, Miligkos D, Arambage K, Torbe E, et al. British Society for Gynaecological Endoscopy /European Society for Gynaecological Endoscopy Guideline Development Group for Management of Fluid Distension Media in Operative Hysteroscopy BSGE/ESGE guideline on management of fluid distension media in operativehysteroscopy. Gynecol Surg. 2016;13:289-303

4. Moritz ML, Ayus JC. The pathophysiology and treatment of hyponatraemic encephalopathy: an update. Nephrol Dial Transplant. 2003;18:2486-91. 
5. Taskin O, Buhur A, Birincioglu M, Burak F, Atmaca R, Yilmaz I, et al. Endometrial $\mathrm{Na}+, \mathrm{K}+-$ ATPase pump function and vasopressin levels during hysteroscopic surgery in patients pretreated with GnRH agonist. J Am Assoc Gynecol Laparosc. 1998:5:119-24.

6. AAGL Advancing Minimally Invasive Gynecology Worldwide, Munro MG, Storz K, Abbott JA, Falcone T, Jacobs VR, Muzii L, Tulandi T, Indman P, Istre O, Jacobs VR, Loffer FD, Nezhat CH, Tulandi T. AAGL practice report: practice guidelines for the Management of Hysteroscopic DistendingMedia: (replaces Hysteroscopic fluid monitoring guidelines. J Am Assoc Gynecol Laparosc. 2000;7:167-168). J Minim Invasive Gynecol. 2013;20(2):137-48. https://doi.org/10.1016/j.jmig.2012.12.002.

7. Nezhat $\mathrm{CH}$, Fisher DT, Datta S. Investigation of often-reported ten percent hysteroscopy fluid overfill: is this accurate? J Minim Invasive Gynecol. 2007; 14:489-93.

8. Yessayan L, Yee J, Frinak S, Szamosfalvi B. Treatment of severe Hyponatremia in patients with kidney failure: role of continuous Venovenous hemofiltration with low-sodium replacement fluid. Am J Kidney Dis. 2014;64:305-10.

9. Ji DX, Gong DH, Xu B, Tao J, Ren B, Zhang YD, et al. Continuous venovenous hemofiltration in the treatment of acute severe hyponatremia: a report of 11 cases. Int J Artif Organs. 2007;30:176-80.

10. Yaprak M, Turan MN, Tamer AF, Peker N, Demirci MS, Çırpan T, et al. How quickly can acute symptomatic hyponatremia be corrected? Int Urol Nephrol. 2013:45:1805-8.

\section{Publisher's Note}

Springer Nature remains neutral with regard to jurisdictional claims in published maps and institutional affiliations.

Ready to submit your research? Choose BMC and benefit from:

- fast, convenient online submission

- thorough peer review by experienced researchers in your field

- rapid publication on acceptance

- support for research data, including large and complex data types

- gold Open Access which fosters wider collaboration and increased citations

- maximum visibility for your research: over $100 \mathrm{M}$ website views per year

At $\mathrm{BMC}$, research is always in progress.

Learn more biomedcentral.com/submissions 